\title{
The Polythink Syndrome and Elite Group Decision-Making
}

\author{
Alex Mintz \\ IDC Herzliya \\ Carly Wayne \\ University of Michigan
}

\begin{abstract}
How do presidents and their advisors make war and peace decisions on military intervention, escalation, deescalation, and termination of conflicts? How do groups make decisions? Why do they often make suboptimal decisions or appear to be frozen in inaction? The leading concept of group dynamics, Groupthink, offers one explanation: cohesive policymaking groups, such as advisors to the president, often make suboptimal decisions due to their desire for uniformity over dissent, while ignoring important limitations of chosen policies, overestimating the odds for success and failing to consider other relevant policy options or possibilities. But groups, including presidential advisory teams, are often fragmented and divisive. We thus introduce Polythink, a group decision-making dynamic whereby different members in a decision-making unit espouse a plurality of opinions and offer divergent policy prescriptions, which can result in intragroup conflict, a disjointed decision-making process, and decision paralysis as each group member pushes for his or her preferred policy action. This phenomenon is no less problematic or common than Groupthink and explains how otherwise smart, experienced decision-makers can engage in flawed decision-making processes that deeply affect the security and welfare of a country. By shining a light on Polythink's symptoms and consequences, and on the factors that lead to Polythink, we seek to offer actionable policy prescriptions for elite decision-makers to offset the negative attributes of this phenomenon and engage in more optimal policymaking processes. Furthermore, we explain how leaders and other decision-makers (e.g., in business) can transform Destructive Polythink into Productive Polythink, illuminating the potential ways in which this group dynamic may be effectively directed towards sound decisions.
\end{abstract}

KEY WORDS: Groupthink, Polythink, group decision-making, U.S. foreign policy, war, peace, Obama administration

How do policymakers make critical policy decisions? Why do smart, experienced decisionmakers often make what appear to be suboptimal choices? How do groups make decisions? The political psychology of group decision-making can shed light on these important questions.

Decision-making groups can be placed on a continuum of cohesion from monolithic and unified to disjointed and fragmented. The location of a decision-making group on this continuum can have a critical impact on the decision-making process and ultimate policy chosen. Famously demonstrated by Janis (1972), Groupthink is one potential syndrome of cohesive groups. Under Groupthink, groups will make suboptimal decisions due to their desire for uniformity over dissent, while ignoring important limitations of chosen policies, overestimating the odds for success and failing to consider other relevant policy options or possibilities. 
On the other end of the spectrum, groups can be fragmented and divisive. In this contingency, Polythink is a greater concern. Polythink is a group decision-making dynamic whereby different members in a decision-making unit espouse a plurality of opinions and offer divergent policy prescriptions, which can result in intragroup conflict, a disjointed decision-making process, and decision paralysis and inaction as each group member pushes for his or her preferred policy action (Mintz, Mishal, \& Morag, 2005; Mintz \& Wayne, 2016). In many ways, Polythink describes a fragmented and conflicted pattern of decision-making in which relevant actors do not have a strong commitment to each other. Thus, Polythink occurs when there is essentially too much diversity of opinion, rather than too little. This article will examine Polythink's symptoms and consequences, as well as the factors that lead to Polythink in order to offer actionable policy prescriptions for decision-makers to offset the negative attributes of this phenomenon. We will also introduce the concept of Productive Polythink, which can lead to more optimal policymaking processes.

\section{Polythink}

Polythink exists when a plurality of opinions and views leads to disagreement between group members. Indeed, Polythink is relevant to any group (not just decision units), including multiple groups within a decision unit. "Polythink" is derived from the word "poly," meaning "many" ways of perceiving the same decision problem, important goals, and potential solutions (Mintz et al., 2005). Thus, necessary conditions for Polythink are the presence of a plurality of opinions in the group, disagreement, and dissent within the decision unit. Polythink can affect everything from the identification of policy problems, to the potential options considered to address them, to the ultimate choice made. Polythink is essentially the opposite of Groupthink on the continuum of decision-making from "completely cohesive" (Groupthink) to "completely fragmented" (Polythink). The divergence of opinions in Polythink groups will frequently lead to myriad opinions, interpretations of reality, and policy prescriptions, which will make it difficult to formulate cohesive policies.

Polythink thus results from a disjointed decision-making where the level of dissention makes it difficult, if not impossible, for group members to reach consensus regarding (1) the problem they are facing and (2) the best solution to the problem. As a result, Polythink can lead to suboptimal decisionmaking processes that often result in bad decision outcomes. This dissent can also lead to decision paralysis, leaving major policy initiatives stymied by discord and inaction. Polythink characterizes many decision units and contributes to shaping the review of policy options and outcomes. It is thus likely that groups that are handicapped by Polythink will reach a very different decision than groups plagued by Groupthink. ${ }^{2}$

Both Polythink and Groupthink should be considered as "pure" types. In real-world decision-making situations, there is rarely a case of pure or extreme Polythink or Groupthink. It is therefore more useful to think of these two concepts as extremes on a continuum in which "good" decision-making dynamics typically lie towards the middle, whereas defective ones lean closer to the two extremes-the group conformity of Groupthink or the group disunity of Polythink (see Figure 1).

${ }^{1}$ For example, Dan Caldwell (2011) references Ivo Daalder and James Lindsay's work in the book America Unbound, in which they identified three distinct groups within the Bush Administration: assertive nationalists (Dick Cheney, Donald Rumsfeld), neoconservatives (Paul Wolfowitz, John Bolton, Richard Perle), and pragmatic internationalists (Colin Powell, Richard Haass).

2 This focus on small-group dynamics differs from many important characterizations and studies of national security and foreign policy decision-making which focus on a unitary actor (see, for example, Brams, 2003, 2011; Bueno de Mesquita, 1981; Bueno de Mesquita \& Lalman, 1992). 


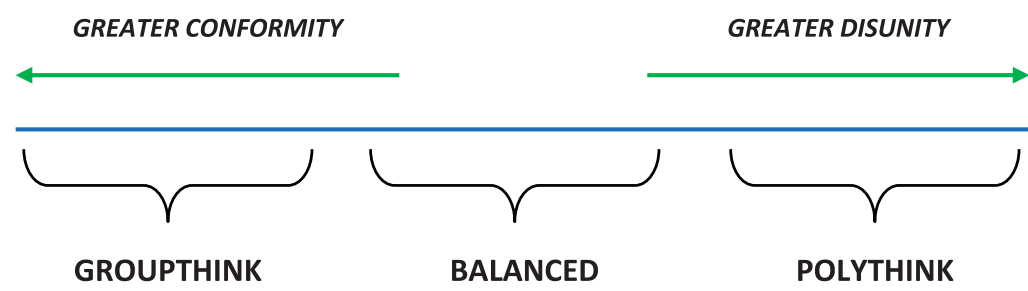

Figure 1. Groupthink-Polythink continuum.

\section{Symptoms of Polythink}

There are a number of important symptoms of Polythink, some of which (confusion, leaks, and framing) are counterintuitive. The presence of these symptoms and pathologies can be used as a diagnostic criterion to determine if Polythink was present in a given decision-making unit on a particular decision problem.

Greater likelihood for intragroup conflict. As group members have different, sometimes opposing or even zero-sum views of the situation and of potential solutions, there is greater likelihood for group conflict and personal disagreements in Polythink. This is in comparison with Groupthink, where group members share common viewpoints. Group conflict may become particularly problematic in long-term planning and implementation, where policy decisions have lasting impact (e.g., there is a large "shadow of the future"), and smaller implementation decisions must be continually made and updated.

As an example for this symptom of Polythink, in the case of the 9/11 fiasco, the destructiveness of this internal conflict to the decision-making process was clear. Chronic disagreement between key branches of the advisory group often impeded successful cooperation on policy development. This bickering demonstrated that indeed, "turf is a powerful thing in Washington" (Clarke, 2004, p. 194), and it often triggered power struggles between the CIA, the FBI, and the military, as the "competing power centers. . .jockey[ed] for influence over counterterrorism policy" (Shultz, 2004, p. 33). ${ }^{3}$

Greater likelihood of leaks. Since group members do not hold uniform views of the decision problem or potential solutions under Polythink, they are more likely to leak information in order to undermine positions they oppose than in a Groupthink situation.

Perhaps the most famous example of leaking negative stories to the press was General Stanley McChrystal's Rolling Stone interview during the first Obama Administration, in which he and his advisors expressed derisive opinions about Vice President Joe Biden, Special Advisor on Afghanistan Richard Holbrooke, U.S. Ambassador Karl Eikenberry, and even President Obama himself (Hastings, 2010). ${ }^{4}$

Confusion and lack of communication. Polythink may increase confusion through willful lack of communication, mixed messages sent from different members of the decision-making unit, as well as inadvertent failures to effectively communicate between and within a diverse decision-making structure. This is likely to confuse the decision-maker and make him or her less clear on the optimal course of action.

As an example for this symptom of Polythink, a major government failure in the months and years leading up to the $9 / 11$ attacks was the oft-cited inability of various key agencies to communicate with each other. And, in fact, analysts often bemoan the fact that "somewhere in CIA there was information that two known al Qaeda terrorists had come into the United States. . Somewhere in FBI there was information that strange things had been going on at flight schools in the United States" (Clarke, 2004, p. 236), yet no one was able to pull these threads of information together to form a

\footnotetext{
${ }^{3}$ The national security policies put in place in the months and years leading up to the 9/11 attacks are discussed at length in Chapter 3 of The Polythink Syndrome (2016).

${ }^{4}$ The Afghanistan Withdrawal is examined in Chapter 4 of The Polythink Syndrome.
} 
complete picture of the impending threat, due to the inability and lack of will of various agencies to share what they knew (Freeh, 2005).

Greater likelihood of framing effects. Polythink may cause some group members to advance biased or selective information to effectively make their point and convince the leader of the efficacy of their ideas (at the expense of others). For example, advisors are likely to frame policies they prefer in favorable lights ("spreading democracy") and those they do not in negative lights ("a potential quagmire"). ${ }^{5}$ The likelihood of members of the group framing a decision problem in opposite directions is greater under Polythink than when there is a group consensus, as in Groupthink. Of course, in Groupthink, framing effects will also be present; however, the frames will tend to be in a single direction rather than in competing ones.

As an example of this symptom, the 2012 U.S. debate over the potential arming of the Syrian rebels demonstrates the role of frames in Polythink debates. The close political aides on Obama's side (against increased involvement in the Syrian conflict) often framed discussion on this issue in terms of the costs of the United States intervening in Syria, while downplaying the many risks associated with not intervening (Rohde \& Strobel, 2014). These advisors emphasized the large amount of weapons already on the ground in Syria and the risk they posed of ending up in extremists' hands (Entous, 2013). In contrast, others such as CIA Director General Petreaus framed the decision in loss termsthe potential loss of the hard-fought gains of the Iraq War as extremists from the Syria conflict spilled over into neighboring countries and the need to intervene to prevent this (Entous, 2013). ${ }^{7}$

Adoption of positions with the lowest common denominator. Because of the many competing voices and ideas, Polythink may create decision situations in which the lowest common denominator becomes the dominant output of the group. Since group members express different or opposing views as to the best potential solutions to a given policy problem, there is less likelihood for the group to "speak in one voice" under Polythink. As such, groups will likely settle on a compromise option that attempts to partially satisfy all (most) parties. As such, each member of the group needs to make some concessions or compromises in his or her organizational and political agendas in order to reach a policy decision that will be palatable to the majority of the group (a difficult hurdle). More powerful groups within the decision unit may also marginalize or even expel members of groups with competing perspectives, thereby imposing their particular views on the decision unit. ${ }^{8}$

An example of this symptom of Polythink are decisions on the pace of the Iraq War drawdown. In essence, there were two main plans on the table for withdrawing troops from Iraq: the 23-month drawdown plan from the military that Obama had inherited from his military commanders and his 16month campaign promise. The 19-month timeline for troop withdrawals that was eventually chosen essentially "split the difference between the sixteen months he promised as a candidate and the twenty-three-month timeline favored by some commanders" (Bruno, 2009). Thus, it was chosen mainly due to its ability to "balance" between various viewpoints, rather than because it was necessarily the optimal diplomatic or military strategy (Bruno, 2009). ${ }^{9}$

Decision paralysis. Often, groups may not even be able to reach a lowest common denominator decision and may instead suffer from complete decision paralysis. This can result in the failure to act to stem or to prevent potential crises or to the adoption of suboptimal, satisficing policies that are often

${ }^{5}$ Unless the persuasiveness and influence of each group member is equal, these frames are unlikely to completely cancel out.

${ }^{6}$ This conception of framing is in line with the well-known discussion of framing effects in Kahneman and Tversky's (1979). While Tversky and Kahneman point to a "loss" or "gain" frame, our use of the term here implies other potential frames as well. For example, the same issue can be framed as a "security problem" or as a "diplomatic problem" with all the requisite differences in approach and issues that those competing frames imply.

${ }^{7}$ See Chapter 7 of The Polythink Syndrome.

${ }^{8}$ Such was the case with the neo-conservative coalition in George W. Bush's administration and the ostracism and eventual resignation of Colin Powell.

${ }^{9}$ See Chapter 5 of The Polythink Syndrome. 
short-sighted and inhibit the long-term planning required in many foreign policy decisions. The many divergent viewpoints present within the decision-making unit under Polythink can cause leaders to freeze up, as they are both unclear as to whether their choice is correct and if it could even be accepted by the rest of their decision-making units and their public. The political costs of reaching a decision may also simply be too high, given the dissent in their own decision unit. Thus, decision paralysis is a primary outcome (e.g., result) of Polythink.

The Obama Administration's 2009 major shift on Iran-from promised engagement on the campaign trail to quick containment once in office-is a primary illustration of this symptom. Essentially, in containing Iran's nuclear ambitions in 2009, the Obama Administration faced a situation with few good options and even fewer options for which consensus could be gained domestically and internationally. There was deep contention over the question of "when to talk, with whom and about what" (Murray, 2010, p. 217). Thus, "Cold War-style containment emerged as the default option for the United States" (Adamsky, 2011, p. 168), not because it was necessarily the most effective policy but because it represented the continuation of existing policy towards Iran at a time when achieving the necessary consensus for a new (and perhaps, better) policy proved too intractable. The administration was paralyzed in terms of its ability to develop new policies, and so it continued with the existing one, essentially delaying a decision until more consensus could be reached. However, in Obama's second term, his new restructured decision unit was able to push forward a new diplomatic policy vis-à-vis Iran. Parallel changes in Iran's decision unit (e.g., Rouhani's rise to power) were also instrumental, of course.

Paradoxically, some of the symptoms of Polythink are similar to those of Groupthink. However, this is the case not because the group is thinking alike or sharing the same views but "because the group is failing to carry out any significant collective thinking" (Mintz et al., 2005, p. 8). As is the case with Groupthink, Polythink is likely to lead to the following:

Limited review of policy options. Polythink can actually lead to a limited review of policy options even though each advisor has distinct policy preferences that should lead to a widening of the policy options considered. This is because the debate within the group can quickly become unwieldy. Thus, decision-makers will often quickly exclude some options from consideration in order to be presented with a more manageable choice set for more thorough consideration (Mintz, 2004).

No room for reappraisal of previously rejected policy options. Similarly, as in Groupthink, the group is less likely to revise its policies if and when other policy options are brought back up for discussion. Unlike in Groupthink, this is not because of overwhelming group consensus that impedes the processing of new information, but because any updating of policies may result in the time-consuming rehashing of previously reconciled disagreements between group members that the leader wishes to avoid.

As these many symptoms demonstrate, Polythink, like Groupthink, is likely to lead to defective, suboptimal decisions; however, the mechanism for these flawed decision-making processes is the group's disunity and diversity rather than the group's unity and conformity.

\section{Measuring Polythink}

Polythink can be operationalized and measured (Mintz, Mishal, \& Morag, 2005). In addition to examining the number and severity of the above symptoms present in a decision-making process, one can determine empirically whether Polythink or Groupthink exists in a group by examining the number of overlapping choice sets of alternatives and dimension sets of group members (Mintz et al., 2005). Such an analysis can reveal the extent of overlap in individuals' "decision matrices" (Mintz et al., 2005). A decision matrix consists of a set of decision alternatives (for example, Do Nothing, Apply Sanctions, Negotiate, Attack) and a set of decision dimensions or criteria (such as political considerations, diplomatic considerations, military dimensions, and economic considerations) (Mintz, 1993). By comparing whether the alternative sets and dimension sets are (1) completely 
identical, (2) partially similar, or, (3) whether there is little overlap in the choice sets and the dimension sets, one can determine whether a Polythink or a Groupthink dynamic exists in a group. Conceptually and empirically, it is thus possible to think about decision units in several different ways. These have important ramifications for the operationalization and measurement of Polythink.

1. The content of the choice set and dimension set: This refers to whether alternatives and dimensions of group members are similar or different and the extent of such variations across group members.

2. Binary (bi-categorical) mode of decision-making versus multicategorical mode: In foreign policy, for example, state decision-makers evaluate alternatives such as use of force or no use of force; sponsor terrorism or oppose terrorism; or in a multicategorical mode (e.g., attack, do not attack, negotiate, apply sanctions). One measure of Polythink is the number of alternatives in the choice set of each decision-maker.

3. One can view decision-making as multidimensional (based on several criteria/dimensions such as the military balance, political audience costs, or deterrence) versus uni-dimensional (e.g., whether the decision will help the leader politically). Consequently, another measure of Polythink is the number of dimensions/criteria in each member's matrix.

4. The size of the decision matrix is also an important criterion in comparing decision-making (Maoz, 1990). Some decision-makers conceptualize a decision problem in a relatively narrow way, while others do so in a more comprehensive and more encompassing way (e.g., by using a multicategorical choice set and a multidimensional dimension set). The size of the decision matrix equals the number of alternatives multiplied by the number of dimensions.

In discussing the measurement of Polythink, it is important to also think of how its presence can be refuted. In order for the Polythink syndrome and dynamic to exist, several symptoms, such as leaks, competing framing efforts, and intragroup conflict should also be present. Polythink is not only multiple viewpoints among group members, which might be normal for any group; disagreement and dissent are critical as well. For example, Polythink appears to have been prevalent at the 2000 IsraeliPalestinian Camp David talks. In a documentary that aired on Channel 10's "The Source" with Raviv Drucker in Israel in November 2015, Saeb Erekat claimed that the Israeli delegation was divided and fragmented, even mentioning specific names of delegates and how their views broke down into different subgroups within the Israeli delegation.

Indeed, one way to distinguish Polythink from Groupthink is by showing that the group has serious disagreements among its members. It is also possible to refute Polythink by showing that the group dynamic fits better with Groupthink symptoms. The overarching prerequisite of Polythink is the plurality of opinions, disagreement, and dissent among group members. Moreover, for Polythink to exist, the majority of symptoms (although not all) need to be present. The symptoms of Polythink thus offer a systematic and testable set of hypotheses. For example, groups under Polythink will likely exhibit more intragroup conflict, leaks, and confusion than Groupthink groups. ${ }^{10}$

\section{Causes of Polythink}

But why does Polythink occur in the first place $?^{11}$ The underlying causes of Polythink boil down to a few key factors. First, the large bureaucracy that characterizes many organizations (not just

${ }^{10}$ There are some exceptions to this; for example, groups that operate in secret (e.g., intelligence units) forbid leaks, yet are often still characterized by Polythink.

${ }^{11}$ Much of this section is adapted from Mintz et al. (2005). 
governmental) means that diverse sets of decision-makers must work together to develop cohesive, beneficial policies while at the same time effectively represent their various constituencies (such as political parties, governmental branches, and respective institutions). Moreover, this same complex bureaucratic structure can often lead to a lack of communication flow that severely impedes the timely, uniform information processing necessary to make expedient, informed decisions. Finally, at a more individual level, members of a decision-making group bring with them vastly different types of decision-making styles, experience, and roles within the group. These diverse perspectives and ways of making decisions hinder the ability of individual group members to see eye-to-eye on important issues. These causes of Polythink can be summarized in five key explanations:

The Institutional, "Turf Wars" Explanation. The well-known phrase "where you stand depends on where you sit," coined by Rufus Miles Jr. (1949, 1978) and popularized by Graham Allison (1971), adeptly summarizes the type of "institutional thinking" that can contribute to Polythink. Under this explanation, the goal of members of the group is to represent their bureaucracy/organization. Thus, presidential advisors, members of the military, intelligence officials, and cabinet members all have their own institutional perspectives and views and interpret and advance plans and proposals from these particular "lenses" and calculations ${ }^{12}$ (e.g., political, coalitionary, institutional, etc.). This well-known tendency to negotiate between various institutional positions is evident in Kissinger's famed observation that "The conclusions of both the Joint Chiefs of Staff and the National Security Council reflect the attainable consensus among sovereign departments rather than a sense of direction" (Kissinger, 1969, p. 227).

Institutional rivalries can contribute to Polythink. Due to intragroup and intergroup institutional competition (for resources, attention, time, credit, promotion), turf battles can arise that hamper information sharing across a variety of intelligence and security agencies, such as the CIA, FBI, and NSA, triggering confusion and miscommunication, key symptoms of Polythink. Moreover, multiple gatekeepers at various organizations may emerge, holding information at control or choke points (Sullivan, 2007) and keeping the information close to their chest (for a variety of organizational and bureaucratic reasons) instead of sharing it.

The Political Explanation. Robert Putnam (1988) coined the term "Two-Level Games" to describe a typical negotiation setting where negotiators "play" at both the international level and the domestic level. As such, they take into account international considerations as well as domestic political considerations (such as political audience costs; see Schultz, 2003). Audiences play an important part in shaping the behavior of elected officials (Rubin \& Brown, 1975). In parliamentary democracies, for example, where governments typically consist of representatives of different parties with different platforms, agendas, constituencies, and interests, a two-level game can contribute to Polythink, as each member of the group represents not only the national interest but also his party and constituencies' interests. Each member of the decision unit has to view his strategy in light of the coalition process and its potential effect on the relationship with different potential partners. Indeed, actors may evaluate a policy choice entirely in terms of how it affects another policy choice or political conflict that is more important to them. This lack of strong group cohesion (because group members come from different political parties or represent different political constituencies) can increase the likelihood of Polythink. In contrast, authoritarian systems are less likely to suffer from Polythink because of the top-down control and fear advisors have of giving dissenting opinions.

${ }^{12}$ In the business world, various issue positions can be advanced by marketing and sales representatives, financial managers, and R\&D managers. Such diversity is common and reflects Polythink in many corporate and business structures. 
The Normative Explanation. Another cause of Polythink is individual, rather than structural. Members of a decision unit can possess different decision-making styles (e.g., such as need for cognition or cognitive complexity), interpersonal relationships (collegial, competitive, distant), and beliefs and worldviews (their operational codes or political ideologies). Steven Walker and associates (1999) analyzed presidential "operational codes" (George, 1969) and belief systems, and have pointed to the importance of normative differences in beliefs among leaders in predicting decisions and action.

These operational codes and normative perspectives also apply to presidential advisors. Members of groups represent not only the national interest but also their personal values and worldviews. Moreover, they have different personal backgrounds inside and outside of government, growing up and throughout their careers. The relative lack of formal "rules of the game" in presidential advisory groups can exacerbate these differences and contribute to "Normative Thinking"-where the goal of members of the decision-making unit is to represent their own world view and normative belief system (Taber, 1992).

The Expert/Novice Explanation. Fiske, Kinder, and Larter (1983) found that novices "employ knowledge-based strategies that differ from those of experts" (p. 393). They process information and recall information in different ways than experts. Specifically, whereas experts often focus on disconfirming evidence and information, novices typically focus on confirmatory information and strategies (Fiske et al., 1983). Naturally, this can have a drastic effect on the prevalence of Polythink. In national security and foreign policy decision-making units, this expert-novice divide generally exists between security experts, diplomatic experts, and political experts, who, given the tendency to specialize, are most likely novices in the others' field of expertise (i.e., a career diplomat will likely not have a strong military background, and a military leader will likely not have trained as a diplomat, etc.). This divide can thus be particularly pronounced when military leaders weigh in on diplomatic solutions and when diplomatic advisors seek to address military concerns. New leaders or advisors may also suffer from an expertise gap that leads to different modes of thinking.

Importantly, however, though experts do indeed use different decision-making strategies than novices, expertise does not always lead to better decision-making. Psychological and decision-science research has often demonstrated that, surprisingly, experts are frequently little better than chance at predicting or forecasting events (Tetlock, 2005; Tversky \& Kahneman, 1974). Moreover, novices are able to make accurate and efficient decisions when the judgments required are novel or innovative (Jervis, 1976). This means that expertise is often "functional if the environment is stable but has high costs if it is not" (p. 196) — a paradox that has important implications for both policymaking and its execution. For example, it was not military experts who predicted the changing nature of war in the years prior to the First World War, but "amateurs—novelists and a Polish banker," demonstrating that, within the military at least, major innovations often come from outside the mainstream of the field (p. 199).

The Leader/Followers Explanation. Finally, studies have shown that leaders place significant constraints on the freedom of action of their advisors (Hermann, 2001). The inability of leaders to often share goals, objectives, or strategies with group members, due to fear of leaks or the desire to maintain impartiality and prevent Groupthink, may also contribute to Polythink. For example, a "hands off" management style that gives subordinates a wide degree of autonomy may contribute to Polythink by exacerbating each group member's perceived independence and influence.

In sum, the above discussion would seem to suggest that bureaucracies, constituencies, affiliations, worldviews, and relative expertise all exert a significant influence on the underlying dynamic of a decision-making unit. Collective considerations have to compete in the mind of each member of the team with other interest-based considerations (institutional, domestic-political, and personal) (Mintz et al., 2005). ${ }^{13}$ Thus, the existence of Polythink can be thought of as a contingent phenomenon-

${ }^{13}$ The five causes of Polythink listed above are not mutually exclusive. There is a natural overlap between some of these considerations. For example, the political positions of members of the coalition and their personal worldviews are related constructs that often interact. 
dependent on a variety of factors such as government structure (e.g., parliamentary vs. presidential) and advisory group structure (competitive vs. collegial). Thus, contextual variables such as the level of controversy surrounding an issue, a fragmented political system, and conflicting bureaucratic, institutional, and political agendas and interests of group members are likely to increase the probability of Polythink.

Leadership style is also critical in impacting the group dynamics, as it affects the way advisory systems are structured, organized, and engineered (Hermann \& Preston, 1994). Margaret Hermann (2001) produced a typology of leadership styles consisting of four categories: crusader, strategic, pragmatic, and opportunistic. We believe this typology can also help predict Polythink and whether this Polythink will be productive or destructive. The crusader challenges political constraints and is closed to new information (Hermann, 2001). The opportunistic leader, in contrast, "is mindful of political constraints and pursues information" (Mintz \& DeRouen, 2010, p. 117). This type of leader will not risk alienating politically important actors. The strategic leader "challenges constraints but is open to information" (p. 117). This leader is bold politically "but circumspect when it comes to acting out these ambitious aspirations" (p. 117). Finally, the pragmatic leader respects political constraints but is closed to information. Which type of leadership style can best predict Polythink? It is clear that a prerequisite for productive Polythink is openness to information from group members, even if the information they provide contradicts the one the leader seeks. Consequently, the pragmatic leader and the opportunistic one are more likely to benefit from Polythink, whereas the crusader and strategist may either ignore divisions within their advisory system or even forbid such divisions.

The composition of the decision unit making decisions, the group dynamics within this unit, and the relationship between the decision unit and other groups affect the choices it makes. Understanding these dynamics is crucial to explaining, predicting, and improving national security and foreign policy decisions, business and corporate decisions, and individual decisions.

Table 1 classifies cases of U.S. foreign policy since early 2001, according to their dominantgroup decision dynamic.

\section{Can Polythink Be Beneficial? The Productive Polythink Dynamic}

Polythink often leads to decision paralysis and poor decisions. However, under what conditions might Polythink result in good decisions? In other words, how can Polythink be beneficial? At the extreme, Polythink could be irreversible (i.e., a badly fragmented group cannot be applied toward a positive purpose because the degree of combativeness creates irreversibly negative effects). However, in many cases, political officials/business executives/managers/other group leaders can benefit from Polythink if they can leverage positively the plurality of opinions presented to them in a group setting en route to forming a decision. For example, if a leader can take the diverse feedback of group members and channel it into one comprehensive viewpoint, articulated in one unified voice, it may actually be beneficial to have diverse input in the decision.

There are obviously examples of decisions where diverse opinions/visions were reconciled and resulted in a positive policy outcome. For example, regardless of how individuals judge the actual outcome of the Surge, the decision on the surge of U.S. forces in Iraq is a prime example of how the Administration consulted with multiple groups and experts to engage in a relatively balanced decision-making process in terms of evaluating multiple, even conflicting, views and reconciling them to formulate a cohesive policy. Likewise, President Obama's decision to draw down the number of troops in Iraq exhibited some serious disagreements, but it was supported by nearly $75 \%$ of the U.S. electorate (Jones, 2014), who considered it better than the status quo outcome-at least at the time the decision was taken (though this view is increasingly being challenged as ISIS emerges as a major threat in Iraq and Syria). Stated differently, divergent opinions do not always lead to a bad 
Table 1. Groupthink and Polythink in American Foreign Policy

\begin{tabular}{ll}
\hline GROUPTHINK & \multicolumn{1}{c}{ POLYTHINK } \\
\hline & Pre-9/11 Security Policy \\
Entry into Afghanistan War & Exit from Afghanistan War \\
Entry into Iraq War & Exit from Iraq War \\
& 2009 Iran Sanctions \\
& 2012 Syria Sanctions \\
& 2013-14 Kerry Peace Process in the Middle East
\end{tabular}

Tactical Issues Surrounding 2014 U.S. Decision to Attack ISIS

Source: These cases are analyzed in Mintz and Wayne (2016).

Note. These cases represent significant American foreign policy decisions in the Middle East since the 9/11 attacks, an area of tremendous strategic interest and policy importance for the United States and the world. Importantly, in assessing the presence of Groupthink or Polythink in these decisions, the quality of the outcome is less relevant than the process and dynamic of the decision itself. We thus do not make normative claims regarding the relative correctness of the policy chosen, only of the decision-making process behind this choice.

decision. Managed, Productive Polythink can even be beneficial to the decision-maker as it could reduce the biases of individual group members, as we explain below.

One way that Polythink - channeled effectively — can be beneficial to a decision-maker is reducing biases of information processing, judgment, and choice in group settings. Cognitive biases are defined as "predictable errors in the ways that individuals interpret information and make decisions" (Kahneman \& Renshon, 2009, p. 79). Scholars of decision-making under risk have detected several common biases in decision-making (Forman \& Selly, 1996; Jervis, 1976; Mintz \& DeRouen, 2010) that Polythink may help prevent. This is not the case with Groupthink, which raises the likelihood for a group to exhibit many of these cognitive and information processing biases. Interestingly, many of these cognitive biases are more "hawkish"-oriented in that they make decision-makers "not only more likely to see threats as more dire than an objective observer would perceive, but also likely to act in a way that will produce unnecessary conflict" (Kahneman \& Renshon, 2009, p. 79). Some of the more well-known biases include:

1. Shooting from the hip. This entails making spur of the moment, unplanned decisions. Since group members in a Polythink dynamic express a plurality of opinions, including dissenting views, it is less likely that the group as a whole will be able to make a shootfrom-the-hip decision. Group members who have opposing views are simply more likely than in a Groupthink setting to introduce such views and challenge the prevailing one, making it hard, all things being equal, for the group leader to make impulsive decisions.

2. Locking in. "Locking in" is focusing exclusively on a preferred policy option while ignoring critical information that contradicts this policy option. This bias is much more likely to occur in a Groupthink setting than in a Polythink dynamic. This is because in Polythink, there is a plurality of opinions and views that reduces the probability of all group members to share and advocate the same policy option. With Polythink, there is a greater probability of at least some dissent among group members, including the introduction of an alternative course of action or even a set of competing alternatives.

3. Wishful thinking. Though some views within a Polythink group may represent wishful thinking, other views are likely to not exhibit such bias. Consequently, compared with Groupthink, there is less likelihood for wishful thinking when people express (and are thus exposed to) multiple views than when they share the same (e.g., wrong) view. 
4. Ignoring critical information. In a Polythink dynamic, group members are also less likely to ignore critical information compared with the Groupthink dynamic. This is because the diverse group is more likely to point to, or even highlight, some obstacles and challenges to the preferred course of action. However, because members of the group suffer from a Polythink syndrome, their collective view may be more radical than the view of each one of them, a phenomenon known in the psychological literature as Risky Shift (or group polarization effect). This may lead to the radicalization of the group's recommendation.

5. The poliheuristic bias. This bias refers to when decisions are made only following the elimination of options that are particularly negative on a singular noncompensatory dimension (usually political calculations; Mintz, 2004). The poliheuristic bias is less likely to occur in a Polythink dynamic because conflicting political and institutional agendas and interests often neutralize each other in the process. In other words, group members have diverse opinions in a Polythink setting, so while some members may be susceptible to a poliheuristic bias, the group itself may actually be less prone to such a bias.

6. Focusing on short-term benefits rather than on long-term costs. In a Polythink environment, it is more likely that some members will focus on short-term gains whereas others will focus on long-term costs than in Groupthink where the group is more homogenous in its position and opinion. This can be beneficial to the decision-maker.

7. Preference over preference. Closely related to the "Lock In" bias is the "Preference over Preference" bias of group members. This bias, whereby one overarching course of action is already preferred (e.g., "military action"), but the preference ordering of the suboptions is unclear (e.g., "ground forces" or "missile attacks"), is more likely to occur in a Groupthink process with a directive leader than in a Polythink process. This is because divergent opinions represent a plurality of preferences. Such overarching preferences govern the decision and ultimate choice.

8. Overconfidence. The group as a whole may be less susceptible to overconfidence bias or "positive illusions" (Kahneman \& Renshon, 2009) as various members of the group who exhibit more opposing views may cancel/neutralize each other in overconfidence and underconfidence. In fact, the plurality of viewpoints may hinder overconfidence, as for many of the views presented there is a counterargument and an opposing view.

\section{Engineering Productive Polythink}

Polythink is thus, in many ways, a double-edged sword. Given the ability of Polythink to attenuate several biases in decision-making (as highlighted above), Polythink has the potential to be beneficial to a decision-maker, if channeled effectively. However, the existence of Polythink symptoms in groups typically means group conflict, confusion, leaks, selective information processing, framing and counterframing, and suboptimal, lowest-common-denominator decisions. Turning Polythink into an asset in decision-making is, therefore, challenging, as one needs to overcome its negative symptoms and consequences. Though "it is a Washington truism that every White House likes Cabinet consensus and hates dissent" (Ignatius, 2013), dissent in any group (and especially in Washington) is common. How can Polythink lead to high-quality decisions? Can a "clever" choice architecture that is built around Polythink lead to good decisions? How might an executive or leader turn Polythink into an asset rather than a liability? Under what conditions of Polythink can the quality of decision-making actually improve?

In this section, we show how the presence of Polythink might be converted from a harmful to helpful feature in the context of collective decision-making and suggest five ways that a leader might use to accomplish this, providing some examples to illustrate how this was achieved in the past by U.S. presidents. 


\section{Design and Successfully Manage Your Decision Unit}

The key to overcoming Polythink and Groupthink lies in the concept of Decision Unit Engineering. Decisions are shaped and influenced by the composition of the Decision Unit (DU) (Russett, Starr, \& Kinsella, 2006). As such, executives in business, politics, domestic policymaking, foreign policy, national security, and other domains need to carefully compose the decision unit in advisory groups to ensure high-quality decisions. Other things being equal, a quality process is likely to lead to better decisions than a nonsystematic, intuitive, unstructured process.

There is plenty of historical evidence that shows that poor decision-making processes lead to poor decisions. However, there are numerous historical and contemporary examples and case studies that show that this is not always the case and that a more organized decision-making process does not always lead to a "better" decision.

The classic example that "good, systematic processes do not necessarily lead to good decisions" is, of course, the series of decisions made by former Secretary of Defense Robert McNamara and the Pentagon during the Vietnam War. Many have claimed that McNamara's decisions before, during, and towards the end of the war were made carefully and systematically. Yet, this led to a bad outcome-a foreign policy fiasco: American and Vietnamese casualties were heavy, and the end result, the Vietnam syndrome, was a failure, from the point of view of the U.S. administration, the mass public, and the South Vietnamese government.

The first recommendation we offer for productive Polythink, to enhance the likelihood of successful group decisions, is to focus on the Decision Unit Architecture when initially forming advisory units. Policymakers should try to think of the policies and solutions they want to achieve and implement down the road and design their Decision Unit to meet these goals. This should be done preferably in a balanced decision mode, where there can be "healthy" divergent perspectives among group members but a general consensus on policy goals and overall direction of the group. An ideal decision-unit structure would be balanced, with some diversity of opinions but overall consensus on strategic goals and agenda. This balance can be thought of as "Con-Div" dynamic, with some convergence and some divergence of opinions (see Mintz \& Wayne, 2016).

Indeed, functional decision units are often governed by group decision rules (Hermann, 2001). If such groups do not use rules such as deciding by majority or unanimity in decision-making, or by simply following the leader or another decision rule, it can lead to chaos. The more established these rules are, the more stable the decision unit.

One intriguing example of Decision Unit engineering can be found in the deliberate construction of President Obama's second-term team. One of the characteristics of this advisory group is its more unified worldviews including group members' conception and view of limitations of American military power than the more diverse "team of rivals" group that characterized Obama's first term. Many analysts viewed this as a deliberate move by the President, a result of the discord he faced in his first term in office amongst his cabinet members. It was predicted early on in the second term of the President that the new team would have a top-down consensus (Ignatius, 2013). And indeed, in the second term, the Obama Administration has often been critiqued as veering further and further into the realm of Groupthink as Obama loyalists gain influence in the decision-making unit. Obviously, the composition and dynamic of advisory groups to the President are likely to have implications on U.S. foreign policy and national security decisions. ${ }^{14}$

14 Thus, for example, during Jimmy Carter's term as President of the United States, then secretary of State Cyrus Vance and National Security Advisor Zbigniew Brzezinski had very different views and philosophy on how U.S. foreign policy and national security should be conducted. And during the Nixon presidency, the president's national security advisor, Henry Kissinger, and Nixon's Secretary of State, William P. Rogers, often clashed on policy direction, issues, and influence. 


\section{Leverage Polythink in Brainstorming}

Polythink can be very beneficial to decision-makers in brainstorming. One of the key principles of brainstorming is taking advantage of diverse viewpoints to consider a wide array of options before arriving at a good choice. The decision-maker is given the ability to deliberate the pros and cons of various policy options. Thus, Polythink can prove useful and constructive in brainstorming. For example, leaders of a group and other key decision-makers can ask group members for their advice and input and use this information to brainstorm about potential consequences and optimal courses of action, plans, and solutions. Leaders can also have advisors utilize "good cop, bad cop" roles, which can also be helpful when the team must negotiate with other states or regimes. More analytic and technology-savvy leaders can even ask group members to construct decision matrices (with or without the use of the Decision Board software) and compare these individual matrices to identify similarities and differences, with the ultimate goal of evaluating a comprehensive decision matrix that represents such diverse views. When Polythink is evident, the group leader can also subdivide the group into small subgroups who can each present the subgroup's view. These will be discussed by various subgroups and elevated to the next level of discussion. They can be consolidated eventually into a group decision. In practice, establishing joint policy desks for sharing and analyzing information originating from a variety of sources (e.g., various intelligence agencies) is another way to reduce Polythink in a group.

\section{Use Polythink as a Divide and Conquer Tactic}

In some situations, where Polythink is evident in a group, leaders can actually exploit and leverage the Polythink dynamic for their benefit. ${ }^{15,16}$ For instance, it might be useful for leaders if the opinions of group members in an advisory group are diverse, as this might enable the leader to have more freedom of choice among those opinions. This is because there are supporters in the group for the various different policies they propose (Janice Stein, personal communication, 2012). In other words, Polythink divisions among group members can paradoxically provide leaders with more flexibility than the homogenous Groupthink view, for example, if the group promotes an opinion which contradicts the view of its leader. In the decision to rescue the U.S. hostages from Iran, President Carter made the decision to pursue the military option while keeping Secretary of State Cyrus Vance, who opposed the mission, out of the loop. The president relied on the advice of others in the advisory unit.

Recently, in the Geneva negotiations of the G5 + 1 with Iran in November 2014 regarding its nuclear program, a plurality of opinions and disagreement was apparent. This kind of dissent can paradoxically legitimize the ultimate decision, as the public sees that even conflicting and challenging opinions were taken into account in making the decision.

\section{Use Polythink to Subdivide Major Policy Issue into Smaller, More Manageable Decision Problems}

Group leaders can leverage the expertise and knowledge of group members in different policy areas and domains to help shape their own decisions. For example, President Bush leveraged the expertise of various think tanks in Washington DC and experts in Congress in his decision on the Surge in Iraq. While the President did not end up taking the advice of all groups and think tanks, he benefited from their diverse viewpoints. There are at least two reasons it is important for the chief executive to listen to diverse opinions: (1) the leader/politician can claim credit for instituting and embracing a bipartisan approach, which is rare in Washington; and (2) by consulting groups that do not even agree with the policy, the chief executive can often not only coopt opponents, but also provide political and institutional cover, diffuse responsibility, and reduce the amount of criticism if 
things do not go well and/or as planned. This was apparently the case with Truman's decision to execute the nuclear attacks on Japan during World War II (Pinter, 2013).

In the summer of 2013, President Obama turned to Congress to seek authorization for the use of force against the Assad regime in Syria. As the public and Congress disapproved of such an act, the President decided to reach an agreement with Russia's Putin on the removal of chemical weapons from Syria.

Polythink can also be turned into multiple advocacy if, for example, the group leader transforms opposing viewpoints into strategic, beneficial input. Multiple advocacy and the so-called "competitive advisory system" are typically planned in advance by the decision-maker to generate multiple opinions, even devil's advocacy. Productive Polythink is the ability of the group leader to incorporate opposing viewpoints into a "good" decision, without a priori planning or soliciting such advice. In other words, it is making the best out of a potentially detrimental situation.

\section{Use Decision Support Systems for Objective, Polythink-Free Decision-Making}

Another method of countering unbalanced, pluralistic decision-making views is through the use of analytic tools such as a Decision Support System. The use of an objective, computerized system may be one way of assisting chief executives to avoid Polythink and Groupthink in their decision unit. One such system is the Decision Board computerized platform developed by Mintz, Geva, Redd, and Carnes (1997). The benefits of using a Decision Support System (DSS) in group decision-making are:

- The DSS can display a wide range of policy alternatives, including those that the president/ executive may not typically use and policy alternatives that can be viewed as representing "outside the box" ideas.

- A Decision Support System can take into account a large set of criteria for selecting the optimal policy for the President. The human mind cannot comprehend and calculate so many dimensions of a decision without a computerized system that aids the policymaker formulating their decision. This is another advantage of using such systems.

- A Decision Support System enables the president and his advisors (and other group leaders) to conduct IF-THEN analysis, based on various dynamic and static assumptions and scenarios to determine the optimal outcome of the decision. One cannot expect the president to actually use DSSs, but the executive's advisors can and probably should carefully examine the consequences of a wide range of policy alternatives to determine optimal outcome.

- A Decision Support System can lead to a careful evaluation of alternatives and dimensions in a comprehensive way, thus overcoming many of the problems associated with the Polythink syndrome, biases in information processing, biases in group dynamics and naturally in individual decision-making. It can also assist the policymaker in organizing alternatives in a clearer, more controlled manner. In addition, it has the benefit of displaying all the information in a systematic way for key decision-makers.

Thus, for example, the use of a Decision Support System by advisors of President Obama during deliberations on the Iran nuclear issue could have aided the President and his advisors to determine and decide on "best" policy options to pursue, in a relatively objective, systematic way, while neutralizing information processing biases and other cognitive biases, even in the chaotic and ever-changing environment of the Middle East. This may help the chief executive avoid the Polythink and Groupthink syndromes. Of course, some of these strategies are more plausible than others from a practical standpoint (e.g., it is more likely that a leader can engage in decision unit architecture than that he or she will actually employ a mechanized DSS). 


\section{The Bottom Line}

Polythink and Groupthink are generic concepts that are applicable to a myriad of realms. These concepts can be applied to a variety of arenas and domains, in domestic, foreign and national security policymaking, corporate and business decisions, international and domestic organizational decisions and even personal decisions. For example, Polythink exists widely in business and the corporate world as well. Indeed, Polythink is applicable to any group decision. Tactics to transform Destructive Polythink to Productive Polythink may lead to better outcomes, but this often depends on the leader's style, charisma, vision, and the special circumstances of the group. Consider, for instance, the effect of Polythink or Groupthink on budgetary decisions in business and industry, nonprofit organizations and at the local, state, or federal level. It is clear that, in government, such small-group dynamics affect the ultimate choice and allocation and distribution of resources, for example, to national security versus social welfare programs - what is known as the "guns" versus "butter" dilemma in budgeting. Essentially, Polythink and Groupthink affect decisions whenever there is more than a single decision-maker. These group dynamics have broad applicability worldwide, beyond the United States, of course.

Thus, Polythink is essentially a global phenomenon, not confined to one country or to one society or to a specific governmental system. Transforming Destructive Polythink to Productive Polythink is key for decision-makers who hope to harness the diversity of their advisory teams to improve the policymaking process. Engineering the decision unit to follow a balanced structure can steer the decisionmaking process away from the "defective" Groupthink and Polythink dynamics and ensure a more balanced evaluation of policy alternatives en route to "good" decisions.

\section{Alternatives to Polythink}

Previous work on group decision-making processes, including presidential advisory systems, have identified several related, but distinct, concepts relevant to the Polythink dynamic. Below, we outline various strategies and structures of group decision-making that may directly affect the prevalence of Polythink in group decision-making processes.

\section{Multiple Advocacy}

Polythink may sound similar to Alexander George's (1972) conception of "multiple advocacy"a decision-making strategy whereby leaders seek to "harness diversity of views and interests in the interest of rational policymaking" (p. 751). However, Polythink is distinct from this idea, in that multiple advocacy is a type of structured, purposeful Polythink process, in which the leader capitalizes on the already existing Polythink dynamic to carefully structure and brings together the divergent opinions of group members into a single, cohesive policy direction. Thus, whereas multiple advocacy is a type of Polythink (a type of productive Polythink), most forms, structures, and variants of Polythink are not multiple advocacy. Polythink is a by-product of group dynamics that often triggers destructive consequences, rather than a strategic policy, such as multiple advocacy, that is directed and designed by a leader for the purpose of making informed foreign policy decisions.

The multiple advocacy model, rather than "discouraging or neutralizing internal disagreements over policy," would harness this diversity towards productive ends. George relies on a centralized management model in order to avoid devolving into a nonstructured and unbalanced debate that could potentially paralyze the decision-making process. However, oftentimes, this structured style of management is faulty or nonexistent-when the decision-making group does not agree with the leader, when the leader himself is conflicted, when there are too many 
competing voices, and more. Moreover, multiple advocacy can only work when there is relative parity in terms of power and persuasive skills among all members of the decision unit. This ideal is very difficult to reach in practice. Thus, the multiple advocacy model can be construed of as a type of structured, "ideal" Polythink process, with productive consequences, provided that the group leader adequately structures, leads, and brings together the divergent opinions of group members into a single, cohesive policy direction.

\section{Distributed Decision-Making (DDM)}

Distributed Decision-Making can be defined as "the design and coordination of connected decisions" (Schneeweiss, 2003, p. 3); a model whereby there is a set of related decisions which are distributed across a wide set of organizational decision-makers. Distributed decision-making constitutes therefore, a related but distinct concept to Polythink. The concept originated in the study of social movements (Brown \& Hosking, 1986; Klandermans, 1988), whose distributed, web-like leadership structure did not fit into typical centralized models of leadership. In distributed decision-making, the decisions are not made by one single leader, but rather a series of smaller, interrelated decisions are made by many individuals within an organization, requiring some degree of coordination between actors. The decision-makers are related by means of their organizational roles, which give them full or partial authority and responsibility for certain areas of the decision domain (Sage, 1991).

Thus, it is clear that Distributed Decision-Making is somewhat related to Polythink in that it involves a variety of decision-makers making interdependent decisions that require a degree of coordination in order to be cohesive. However, DDM should be seen more as a potential cause or contributory factor of Polythink. In other words, if this diffuse policymaking process is not properly managed by some type of hierarchical leadership at the top, it can easily descend into chaos or paralysis as each decision-maker inserts their own opinions, values, and worldviews into each of their interrelated decisions, failing to coordinate small decisions into one overarching large policy. Indeed, often in national security policy, it is possible to witness the way in which Distributed Decision-Making exacerbates Polythink. The State Department will make decisions on foreign aid and diplomacy work; the Department of Defense will work to strengthen homeland security; the CIA will focus on intelligence; and the army will seek to maintain military gains in the field. However, in the end, each of these decisions impact the other and must be coordinated up the hierarchical ladder to the president who job it is to ensure the cohesion of the overall foreign policy picture, controlling the potential negative impact of the military industrial complex's distributed nature.

\section{The Competitive Advisory System}

The competitive advisory system is another strategy that has often been put forth as a method to counteract Groupthink (Johnson, 1974). In a competitive advisory system, leaders will ask their advisors to vigorously argue their competing viewpoints in front of the leader rather than shielding him or her from the messy debate process over various policy options. In this system, the leader will keep his or her personal views on the issue hidden until late in the process, after a thorough and full-fledged debate has taken place between the advisors. In this way, the leader can learn the pros and cons of each strategy and be less likely to ignore potential flaws with a preferred strategy. This is because the advisors do not know the leader's preference and are thus less likely to shield negative information concerning the strategy for professional gain or in the interests of deference. By keeping his or her views on the issue hidden or neutral until late in the decision-making process, the president is effectively playing "the neutral or honest broker" role himself (Burke, 2005). FDR is a prime example of this strategy (Pfiffner, 2005). 
In contrast to the Competitive Advisory System, Polythink is more of a reflection of an underlying group dynamic than an explicit choice by the leader to structure his or her advisory system in a specific way. Thus, similar to the idea of Multiple Advocacy, the Competitive Advisory strategy can help groups leaning towards the Groupthink end of the spectrum and potentially hurt groups leaning towards the Polythink end of the spectrum.

In other words, the structure of the leader's advisory group can play an important role in fostering a Polythink decision-making dynamic. The decision-making literature typically identifies three main forms of advisory groups - competitive, collegial, and formal (Burke, 2005; Johnson, 1974; Mitchell, 2005). Each system has the potential to mitigate or exacerbate Polythink (or Groupthink) in different ways. For example, a collegial style will be more likely to lead to Groupthink due to the close relationship fostered between the leader and his advisors. The competitive system, on the other hand, may be more predictive of Polythink in that dissenting views of various group members are freely expressed, perhaps even leading to group conflict. The formal system may mitigate the risks of both Groupthink and Polythink by providing a more structured system that guides the advisory and decision-making process.

\section{Conclusion}

In this article, we discussed the Polythink syndrome, symptoms, and explanations. Polythink is quite common in groups. As a group decision-making model, Polythink can be contrasted with Groupthink. The composition of the decision unit and intragroup dynamic affect the decisions leaders and other policymakers make. It is safe to say that a Polythink-type group will generate, in many instances, policy recommendations that are very different than those generated by a group characterized by Groupthink. Thus, these distinct models of group decision-making lead to different predictions, postdictions, and explanations. Indeed, an important future research agenda is to examine paired samples of case studies with "good" and "bad" outcomes to examine the different group dynamic that was present in each. Appreciating the importance of group dynamics of the decision unit is important and leads to predictions that cannot otherwise be reached.

\section{ACKNOWLEDGMENTS}

Correspondence concerning this article should be addressed to Alex Mintz, Lauder School of Government, Diplomacy and Strategy, IDC Herzliya, Herzliya, Israel. E-mail: mintz.alex@idc.ac.il

\section{REFERENCES}

Adamsky, D. (2011). The war over containing Iran: Can a nuclear Iran be stopped? Foreign Affairs, 90(2), 155-168.

Allison, G. T. (1971). Essence of decision: Explaining the Cuban Missile Crisis. Boston, MA: Little, Brown.

Brown, M. H., \& Hosking, D. M. (1986). Distributed leadership and skilled performance as successful organization in social movements. Human Relations, 39(1), 65-79.

Brams, S. J. (2003). Negotiation games: Applying game theory to bargaining and arbitration. Routledge Advances in Game Theory 2.

Brams, S. J. (2011). Game theory and politics. Mineola, NY: Courier Dover.

Bruno, G. (2009). A costly exit from Iraq. Council of Foreign Relations, March 6. Retrieved from http://www.cfr.org/ iraq/costly-exit-iraq/p18681.

Bueno de Mesquita, B. (1981). The war trap. New Haven, CT: Yale University Press.

Bueno de Mesquita, B., \& Lalman, D. (1992). War and reason: Domestic and international imperatives. New Haven, CT: Yale University Press. 
Burke, J. P. (2005). The contemporary presidency: Condoleezza Rice as NSC Advisor: A case study of the honest broker role. Presidential Studies Quarterly, 35(3), 554-575.

Clarke, R. A. (2004). Against all enemies: Inside America's War on Terror. New York, NY: Free Press.

Entous, Adam. (2013, March 29). Inside Obama's Syria debate. Wall Street Journal, March 29. Retrieved from http:// online.wsj.com/articles/SB10001424127887323639604578368930961739030

Fiske, S. T., Kinder, D. R., \& Larter, W. M. (1983). The novice and the expert: Knowledge-based strategies in political cognition. Journal of Experimental Social Psychology, 19(4), 381-400.

Forman, E., \& Selly, M. A. (1996). Decision by objectives. McLean, VA. Unpublished manuscript.

Freeh, L. J. (2005). My FBI: Bringing down the Mafia, investigating Bill Clinton, and fighting the War on Terror. New York, NY: St. Martin's Press.

George, A. L. (1969). The operational code: A neglected approach to the study of political leaders and decision-making. International Studies Quarterly, 190-222.

George, A. L. (1972). The case for multiple advocacy in making foreign policy. American Political Science Review, 66(3), 751-785.

Gordon, M. R., \& Trainor, B. E. (2012). The endgame: The inside story of the struggle for Iraq, from George W. Bush to Barack Obama. New York, NY: Random House.

Hastings, M. (2010). The runaway general: The Rolling Stone profile of Stanley McChrystal that changed history. Rolling Stone, June 22. Retrieved from www.rollingstone.com/politics/news/the-runaway-general-20100622

Hermann, M. (2001). How decision units shape foreign policy: A theoretical framework. International Studies Review, $3(2), 47-81$.

Hermann, M. G., \& Preston, T. (1994). Presidents, advisers, and foreign policy: The effect of leadership style on executive arrangements. Political Psychology, 15(1), 75-96.

Ignatius, D. (2013). Out: Team of Rivals. In: Obama's guys. Washington Post, February 23. Retrieved from www.washingtonpost.com/opinions/david-ignatius-in-obamas-new-cabinet-rivals-out-loyalists-in/2013/02/22/13f2f27e7c73-11e2-82e8-61a46c2cde3d_story.html

Janis, I. L. (1972). Victims of Groupthink: A psychological study of foreign-policy decisions and fiascoes. Boston, MA: Houghton, Mifflin.

Jervis, R. (1976). Perception and misperception in international politics. Princeton, NJ: Princeton University Press.

Jones, J. (2011). Three in four Americans back Obama on Iraq withdrawal. Gallup, November 2. Retrieved from www. gallup.com/poll/150497/three-four-americans-back-obama-iraq-withdrawal.aspx

Kahneman, D., \& Tversky, A. (1979). Prospect theory: An analysis of decision under risk. Econometrica: Journal of the Econometric Society, 47(2), 263-291.

Kahneman, D., \& Renshon, J. (2009. Hawkish biases. In T. Thrall \& J. K. Cramer (Eds.), American foreign policy and the politics of fear: Threat inflation since 9-11 (pp. 79-95). Abingdon, UK: Routledge.

Kissinger, H. A. (1969). Nuclear weapons and foreign policy. New York, NY: W. W. Norton

Klandermans, B. (1988). The formation and mobilization of consensus. International Social Movement Research, 1, $173-196$.

Maoz, Z. (1990). Framing the national interest: The manipulation of foreign policy decisions in group settings. World Politics, 43(1), 77-110.

Miles, R. E. (1978). The origin and meaning of Miles' Law. Public Administration Review, 38(5), $399-403$.

Mintz, A. (1993). The decision to attack Iraq: A noncompensatory theory of decision making. Journal of Conflict Resolution, 37(4), 595-618.

Mintz, A. (2004). How do leaders make decisions? A poliheuristic perspective. Journal of Conflict Resolution, 48(1), 3-13.

Mintz, A., Geva, N., Redd, S. B., \& Carnes, A. (1977). The effect of dynamic and static choice sets on political decision making: An analysis using the decision board platform. American Political Science Review, 91(03), 553-566.

Mintz, A., Mishal, S., \& Morag, N. (2005). Evidence of Polythink? The Israeli delegation at Camp David 2000. Discussion paper, Yale University.

Mintz, A., \& DeRouen, Jr., K. (2010). Understanding foreign policy decision making. New York, NY: Cambridge University Press.

Mintz, A., \& Wayne, C. (2013). Group decision making in conflict: From Groupthink to Polythink in the war in Iraq. In P. Coleman \& M. Deutsch (Eds.), The handbook of conflict resolution: Theory and practice (pp. 331-352). San Francisco, CA: Jossey-Bass.

Mintz, A., \& Wayne, C. (2016). The Polythink syndrome: U.S. foreign policy decisions on 9/11, Afghanistan, Iraq, Iran, Syria, and ISIS. Palo Alto, CA: Stanford University Press.

Mitchell, D. (2005). Centralizing advisory systems: Presidential influence and the U.S. foreign policy decision-making process. Foreign Policy Analysis, 1(2), 181-206. 
Murray, D. (2010). The carcass of dead policies: Lessons for Obama in dealing with Iran. Contemporary Politics, 16(2), 209-223.

Pfiffner, J. P. (2005). Presidential decision making: Rationality, advisory systems, and personality. Presidential Studies Quarterly, 35(2), 217-228.

Putnam, R. D. (1988). Diplomacy and domestic politics: The logic of two-level games. International Organization, $42(3), 427-460$.

Rohde, D., \& Strobel, W. (2014). Special report: How Syria policy stalled under the "Analyst in Chief." Reuters, October 9. Retrieved from http://in.reuters.com/article/2014/10/09/us-usa-diplomacy-obama-special-report-idINKCNOHY 1QC20141009

Rubin, J. Z., \& Brown, B. R. (1975). The social psychology of bargaining and negotiation. New York, NY: Academic Press.

Russett, B., Starr, H., \& Kinsella, D. (2006). World politics: The menu for choice. Boston, MA: Wadsworth.

Sage, A. P. (1991). Decision support systems engineering. Hoboken, NJ: Wiley and Sons.

Schneeweiss, C. (2003). Distributed decision making-A unified approach. European Journal of Operational Research, $150(2), 237-252$.

Schultz, K. (2003). The politics of peace. Paper presented at the Gilman Conference on New Directions in International Relations, Yale University.

Shultz, R. H., Jr. (2004). Showstoppers: Nine reasons why we never sent our special operations forces after al Qaeda before 9-11. Weekly Standard, 9(19).

Sullivan, J. F. (2007). Gatekeeper: Memoirs of a CIA polygraph examiner. Dulles, VA: Potomac Books.

Taber, C. S. (1992). POLI: An expert system model of U.S. foreign policy belief systems. American Political Science Review, 86, 888-904.

Tetlock, P. (2005). Expert political judgment: How good is it? How can we know? Princeton, NJ: Princeton University Press.

Tversky, A., \& Kahneman. D. (1974). Judgment under uncertainty: Heuristics and biases. Science, 185(4157), 11241131.

Walker, S. G., Schafer, M., \& Young, M. D. (1999). Presidential operational codes and foreign policy conflicts in the Post-Cold War world. Journal of Conflict Resolution, 43, 610-625. 